\title{
Biological effects of isoflavones in young women: importance of the chemical composition of soyabean products
}

\author{
BY AEDIN CASSIDY* AND SHEILA BINGHAM \\ Dunn Clinical Nutrition Centre, Hills Road, Cambridge CB2 2DH \\ AND KENNETH SETCHELL \\ Mass Spectrometry Laboratory, Children's Hospital Medical Center, Cincinnati, Ohio 45229, USA
}

(Received 19 September 1994-Revised 30 January 1995 - Accepted 9 February 1995)

\begin{abstract}
To examine the hormonal effects of isoflavones, of which soyabean is a rich source, fifteen healthy nonvegetarian premenopausal women were studied over 9 months. They lived in a metabolic suite for between 4 and 6 months where their diet and activity levels were kept constant and their hormonal status was measured over two or three menstrual cycles. During one (control) menstrual cycle a normal but constant diet containing no soyabean products was fed. Then, over a second complete cycle six subjects consumed a similar diet into which $60 \mathrm{~g}$ textured vegetable protein (TVP)/d, containing $45 \mathrm{mg}$ conjugated isofiavones, had been incorporated. Three participants had $50 \mathrm{~g}$ miso (a fermented soyabean paste), containing $25 \mathrm{mg}$ unconjugated isofiavones, added daily to their diet over a menstrual cycle, and six others consumed $28 \mathrm{~g}$ TVP/d, containing $23 \mathrm{mg}$ conjugated isoflavones. Five participants completed a third diet period where they were randomly assigned to consume either the control diet over a cycle, or a similar diet incorporating $60 \mathrm{~g}$ of a soyabean product which had had the isoflavones chemically extracted (Arcon F). Follicular phase length was significantly $(P<0.01)$ increased and peak progesterone concentrations were delayed with $60 \mathrm{~g}$ TVP but no effects were observed with Arcon F. The increase in menstrual cycle length did not reach statistical significance in the three subjects who ate $50 \mathrm{~g} \mathrm{miso} / \mathrm{d}$, but peak progesterone levels were significantly $(P<0.05)$ delayed. Mid-cycle peaks of luteinizing hormone (LH) and follicle stimulating hormone (FSH) were suppressed with $45 \mathrm{mg}$ conjugated isoflavones as $60 \mathrm{~g}$ TVP $(P<0.05$ and $P<0.01$ respectively). No other changes in sex-steroid hormone levels were observed on any of the other diets. A significant reduction in total cholesterol was found with $45 \mathrm{mg}$ conjugated isoflavones $(P<0.05)$, but not with $23 \mathrm{mg}$ conjugated isoflavone-free Arcon $F$. There was no effect of menstrual cycle phase on transit time.
\end{abstract}

Soyabean: Hormones: Menstrual cycle: Plant oestrogens

Soyabean is a rich source of a number of weakly oestrogenic compounds, isoflavones, which are structurally similar to the mammalian oestrogen, oestradiol. The principal compounds within these classes of phyto-oestrogens have been shown to have weak oestrogenic activity, ranging from 0.002 to 0.001 the activity of oestradiol (Shutt \& Cox, 1972; Martin et al. 1978; Verdeal et al. 1980; Juniewicz et al. 1988). These compounds have an affinity for oestrogen receptors and produce typical and predictable oestrogenic responses when administered to animals, invoking vaginal cornification and uterine hypertrophy in intact immature mice (Evans et al. 1941; Shemesh et al. 1972; Shutt \& Cox, 1972). Oestrogenic compounds can be agonistic or antagonistic to oestradiol $17 \beta$ when they

* For reprints. 
act simultaneously at target tissues (Clark et al. 1977). Antagonistic compounds normally compete for oestradiol $17 \beta$ receptors but fail to stimulate the nucleus to respond fully (Katzenellenbogen et al. 1977). This partial oestrogen agonistic/antagonistic behaviour is a common feature of many weak oestrogens (Jordan, 1990).

In animal models, one isoflavone, genistein, has been shown to function as an antioestrogen. Folman \& Pope (1966) showed that a dose of $1.6 \mathrm{mg}$ genistein inhibited diethylstilbestrol-stimulated murine vaginal and uterine growth by about $40 \%$. A group of ovariectomized Sydney White strain mice that had been administered oestradiol were subsequently given a subcutaneous injection of $10 \mathrm{mg}$ genistein. The amount of measurable oestrogenic activity in the reproductive tract was reduced by $54 \%$ after genistein administration compared with oestradiol alone (Shutt, 1967). In vitro experiments using the MCF-7 cell line showed that the genistein-bound receptor is processed in the nucleus at about the same rate as the oestradiol-bound receptor but it is less effective than oestradiol in activating empty receptor and inducing tight binding to DNA (Martin et al. 1978).

Compounds in soyabean also appear to be active in animal models of breast cancer. Hawrylewicz et al. (1991) showed that soyabean-protein isolate decreased tumours by $50 \%$ in an $N$-methyl- $N$-nitrosourea (NMU) model of breast cancer. Troll et al. (1980) showed a $50 \%$ reduction in experimentally induced X-ray irradiated mammary tumours in rats consuming a powdered soyabean diet. More recently, Barnes et al. (1990) showed that soyabean ingestion led to a reduction in mammary tumour growth in both the NMU and the dimethyl-benz $(\alpha)$ anthracene rat models of breast cancer. In these models, tumour formation was negatively correlated with total dietary isoflavone concentration, and in particular with dietary intake of genistein and urinary isoflavone excretion level. In addition, the results from a follow-up study found that a soyabean product from which the isoflavones had been chemically removed (Arcon F) had no effect on mammary carcinogenesis (Barnes et al. 1990).

Three epidemiological trials have reported a protective effect of soyabean against the development of breast cancer. In two prospective trials, Nomura et al. (1978) found an inverse association between intake of soup made with miso (a fermented soyabean paste), and a trend toward an inverse association between intake of tofu (a soyabean curd) and subsequent risk of breast cancer, while Hirayama (1986) also showed that a high intake of soyabean-paste soup reduced the subsequent risk in Japanese women. A recent case-control study (Lee et al. 1991) found a significant inverse association in premenopausal women between breast cancer risk and soyabean protein intake.

Previously we have shown that isoflavones can modify hormonal status in healthy premenopausal women (Cassidy et al. 1994). In this study we showed that the long-term ingestion of soyabean protein $(60 \mathrm{~g} / \mathrm{d})$ significantly prolonged the length of the menstrual cycle; more specifically, follicular phase length was increased and significant suppression of the mid-cycle surges of the gonadotrophins, luteinizing hormone (LH) and folliclestimulating hormone (FSH) occurred. However, soyabean products contain numerous other compounds that may be biologically active, and it is also uncertain whether a dose-response effect may exist.

Isoflavones occur naturally in plants either as highly polar glycoside conjugates, for example daidzin and genistin, or in the unconjugated form, for example daidzein or genistein. On ingestion the conjugates are hydrolysed by the intestinal glucosidases to release the unconjugated daidzein and genistein (Setchell et al. 1984). The extent of absorption may be dependent on the chemical form of the isoflavones, in that the unconjugated isoflavones, because of their amphiphilic properties, may be more readily absorbed and therefore more bioavailable than the highly polar conjugated species. 
Textured vegetable protein (TVP) and tofu (soyabean curd) contain high levels of conjugated isoflavones while in fermented soyabean products such as miso approximately $90 \%$ of the isoflavones are present in the unconjugated form (Coward et al. 1993).

In the present study we have therefore assessed (1) the effects of unconjugated isoflavones, (2) the effect of half-dose conjugated isoflavones and (3) the effect of an isoflavone-free product, Arcon F, on hormonal status. These results are compared with some of those of full-dose conjugated isoflavones (Cassidy et al. 1994).

\section{METHODS}

\section{Protocols}

Four different studies were carried out and a total of fifteen non-vegetarian female students, age range 20-29 years, were recruited to participate. All protocols were approved by the Dunn Nutrition Unit Ethical Committee. All participants had regular menstrual cycles and had taken no medication for 6 months before the study. For 4 months before commencement, and for several months after completion, each individual monitored their basal body temperature at the same time each morning to determine if their menstrual cycles were ovulatory. They moved into the metabolic suite at the Dunn Clinical Nutrition Centre at least one cycle before commencing the diets.

The same protocol was followed throughout all studies. All volunteers ate a constant known control diet containing no soyabean for one complete menstrual cycle and a similar diet into which soyabean had been incorporated for another cycle. BMR was estimated from body weight (Schofield et al. 1985), and the energy intake necessary to maintain a constant body weight throughout the diet periods was calculated, assuming a total energy intake: BMR ratio of $1 \cdot 4: 1$. Nutrient intake was calculated from a computerized database of food values (Paul \& Southgate, 1978). Table 1 shows a sample diet and nutrient content for the control period for a subject requiring $8.5 \mathrm{MJ} / \mathrm{d}$. Volunteers requiring more than $8.5 \mathrm{MJ} / \mathrm{d}$ were given the required number of $1 \mathrm{MJ}$ increments containing chocolate, or extra lunch foods. Participants weighed themselves every day, and appropriate adjustments were made to maintain body weight during the first week of the diet. All subjects' meals were prepared in advance, accurately weighed, and deep frozen until required. Frozen and canned food of the same batch were bought in advance to avoid interbatch variability, and bread that contained no soyabean flour was specially purchased for the study. No other food was permitted and all test diets were started on or before the first day of menses. The order of presentation of the control and test diets used in studies 1,2 and 4 was not randomized because of the prolonged effect of consumption of soyabean on menstrual cycle length (Cassidy et al. 1994).

Study 1: $45 \mathrm{mg}$ conjugated isoflavones (n 6). The first menstrual cycle served as a control period. During a subsequent cycle 60 g TVP/d (Protoveg; Direct Foods Ltd., Manchester) was substituted for minced beef, chicken or cod, and the breakfast cereal eaten was Rice Krispies rather than Shredded Wheat in order to maintain the same levels of macronutrients in both the control and test periods. The TVP was given in bolognese, chicken casserole, or vegetable curry and was prepared in advance, weighed and deep frozen until required (Cassidy et al. 1994).

Study 2: $25 \mathrm{mg}$ unconjugated isoflavones (n 3). Participants ate the control diet as before over a complete menstrual cycle, and during a further cycle consumed $50 \mathrm{~g} / \mathrm{d}$ of miso (Muso Co. Ltd., Osaka, Japan). The miso was incorporated into main meals, including chicken curry, beef chilli or shepherds pie in place of minced beef, cod, or chicken. It was 
Table 1. The $8.5 \mathrm{MJ}$ diet used during the control period*

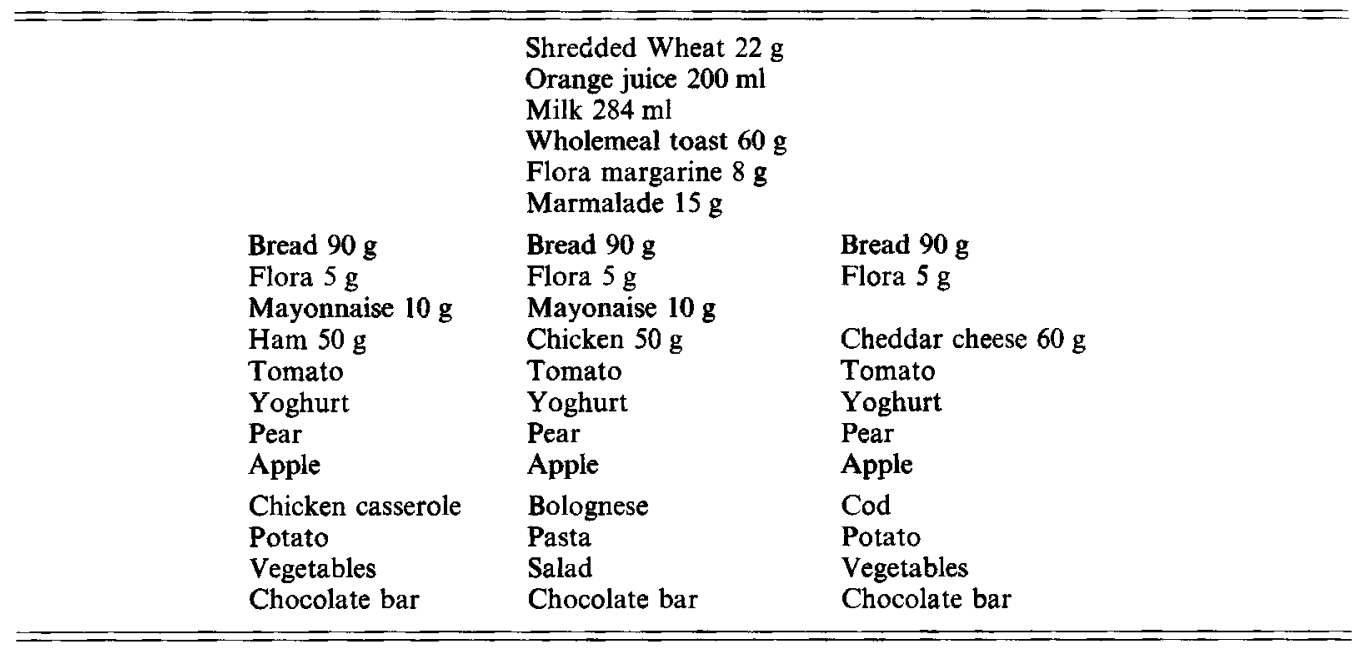

* Mean nutrient intakes were: energy 8.5 (SE 0.1) MJ, protein 97.2 (SE 0.6) g, carbohydrate 258.2 (SE 1.9) g (of which starch 108.3 (SE 2.2) g), NSP $16 \cdot 0$ (SE 0.6) g, total fat 61.4 (SE 0.7) g.

intended to study six volunteers, but due to unpalatibility of the high salt concentration in miso, only three volunteers completed this diet period.

Study 3: isoflavone-free soyabean product (Arcon F) (n 5). In this study the order of presentation of the diets was randomized. Volunteers were assigned randomly to either $60 \mathrm{~g}$ Arcon F/d (isoflavone free; Archer Daniels Midland, Decatur, IL, USA) or a control diet in the first of the two cycles. The Arcon F was given as biscuits or bread. The Arcon F bread rolls replaced the daily bread intake and when the biscuits were given, breakfast cereals were changed from the control diet and less Flora margarine, chocolate and mayonnaise were incorporated to maintain macronutrient levels.

Study 4: half-dose conjugated isoflavones, $23 \mathrm{mg}$ (n 6). Six subjects first ate the control diet over a complete menstrual cycle and in a subsequent cycle consumed half of the isoflavone level as $28 \mathrm{~g} \mathrm{TVP} / \mathrm{d}$ (23 mg isoflavone). The TVP was milled and made into bread rolls, and replaced part of the daily bread intake in the control diet.

\section{Collection of biological samples}

Every $3 \mathrm{~d}$ during each diet period a fasting blood sample and $24 \mathrm{~h}$ urine collection were obtained. Early morning urine samples were collected on all other days. Extra blood samples were collected on the day of ovulation which was detected using 'First Response' ovulation prediction test kits (Carter-Wallace Ltd., Folkestone, Kent) on the early morning urine samples. In addition, throughout the diet periods all faecal samples were collected in order to assess transit time. Follicular phase length was calculated as the first day of menstrual bleeding, up to but not including the day of maximal urinary LH concentration.

The volumes of the early morning urines were recorded and portions taken for quantitative assessment of urinary LH levels to confirm day of ovulation. Volunteers were given para-amino benzoic acid (PABA)-check tablets (Laboratory for Applied Biology Limited, London) on the day of $24 \mathrm{~h}$ urine collections, and volumes were recorded, portions taken and stored at $-20^{\circ}$. Completeness of the $24 \mathrm{~h}$ urine collections was assessed by the PABA-check method (Bingham \& Cummings, 1983). 
The $10 \mathrm{ml}$ blood samples were collected into heparinized tubes between 07.30 and 08.30 hours and immediately centrifuged at $3000 \mathrm{~g}$ for $10 \mathrm{~min}$ at room temperature, using an MSE Fisons Coolspin centrifuge. The resulting plasma was stored at $-20^{\circ}$ before analysis.

\section{Analytical methods}

Transit time and completeness of faecal collections were assessed continuously throughout the study using the radioopaque marker technique (Cummings et al. 1976). The subjects consumed ten radioopaque plastic pellets with each meal, three times daily. Stools were collected from the time the first marker was taken until all had been recovered. Each stool was weighed and then X-rayed to determine marker count and the number of markers recovered was calculated.

Plant oestrogen concentrations were analysed in the test-diet foods using a previously described HPLC technique (Setchell et al. 1987). Homogenized test-diet samples were freeze dried before ethanol extraction. The isoflavone conjugates were then hydrolysed using $\beta$-glucuronidase ( $E C$ 3 2.1 . 31) in $0 \cdot 1 \mathrm{~m}$-acetate buffer for $48 \mathrm{~h}$. The hydrolysate was passed through a pair of reverse-phase bonded silica cartridges, plant oestrogens were eluted with methanol and quantified by HPLC. The miso used in the current study contained $500 \mu \mathrm{g}$ total isoflavones/g and the TVP contained $750 \mu \mathrm{g}$ (study l) and $825 \mu \mathrm{g}$ (study 4) total isoflavones/g.

In study 1 , hormone concentrations were determined using standard commercially available radioimmunoassay (RIA) test kits (DPC UK Ltd., Abingdon, Oxon) (Cassidy et al. 1994). In studies 2,3 and 4, sex-steroid hormone levels were assessed using time-resolved fluorometry (TRF, Delphia system, Wallac UK, Milton Keynes, Bucks). Sex-hormone binding globulin (SHBG), progesterone, oestradiol, LH, and FSH were measured. Interassay coefficients of variation, calculated from the means of duplicates of the control sera were comparable for the two methods; oestradiol $4.9 \%$ (RIA), $3.6 \%$ (TRF); progesterone $8.1 \%$ (RIA), $8.8 \%$ (TRF); LH 9.2\% (RIA), 6.6\% (TRF); FSH 6.6\% (RIA), $6.1 \%$ (TRF) and SHBG $5 \cdot 3 \%$ (RIA), $7.7 \%$ (TRF). In addition, levels of total cholesterol, HDL, LDL and triacylglycerols were analysed using the Cobas-Bio automatic centrifugal analyser (Roche Diagnostics, Welwyn Garden City, Herts). Insufficient plasma was available from study 1 for the analysis of LDL, HDL and triacylglycerol concentrations.

Lyphocheck (Biorad) tri-level immunoassay control sera were used as internal quality control samples and were used for continual assessment of laboratory performance. Interbatch variability was avoided by assessing all samples for a particular subject in one assay and all samples were assessed in duplicate.

\section{Calculations and statistical analysis}

The statistical analysis of the data was carried out on an Apple Macintosh LC computer utilizing Fastet (Systat Inc., Evanston, IL, USA). All results are expressed as means with their standard errors, and differences were assessed using paired $t$ tests. Progesterone levels between the test and control diets were compared by calculating $3 \mathrm{~d}$ running means in order to reduce the error from substantial daily variation. The time taken to reach the peak level in each study was then compared using paired $t$ tests.

\section{RESULTS \\ Body weight}

All volunteers maintained a constant body weight during the study periods. Table 2 shows that mean body weight $(\mathrm{kg})$ was not significantly different between the beginning of the control diets and the end of the $60 \mathrm{~g}$ TVP, $50 \mathrm{~g}$ miso, $60 \mathrm{~g}$ Arcon F or $28 \mathrm{~g}$ TVP diets. 


\section{Results of faecal analysis}

Each subject was given 2100 radioopaque markers over the course of the dietary intervention study, and marker recovery ranged from $98-100 \%$. Thus all six subjects provided essentially complete faecal collections during the two diet periods.

None of the test diets significantly affected transit time over the complete menstrual cycle (Table 2). Mean transit time in the follicular phase of the cycle was significantly longer during the miso diet than in the control period (control $35 \cdot 1$ (SE 4.7) h, miso $45 \cdot 8$ (SE 5.3) $\mathrm{h}$ $(t 11 \cdot 1, P<0.01)$, but no other significant effects on any other diet were observed. Analysis of all fifteen subjects who completed the control period showed that transit time was not affected by phase of menstrual cycle ( $n$ 15, follicular phase 50.9 (SE 5.7) h, luteal phase 54.3 (SE 6.3) h, total menstrual cycle $52 \cdot 6$ (SE 5.8) h).

\section{Menstrual cycle length}

Mean menstrual cycle lengths before the study, and during the control and diet periods are shown in Table 3. There was no significant difference in cycle length between the control and pre-study periods. All participants had a relatively constant menstrual cycle length before commencing the study with coefficients of variation ranging from $0-13.8 \%$ in the four studies. Subject 5 in study 1 had a more variable cycle length, but she had only recently ceased taking oral contraceptives. The subjects in study 4 had significantly longer menstrual cycles than the subjects used in study $1(P<0.001)$ and this may be because the subjects from study 4 were younger (age range 19-21 years study 4, age range 21-29 years study 1). There was a trend towards an increase in menstrual cycle length in study 1; however this did not reach statistical significance (Table 3). The miso diet resulted in a mean menstrual cycle length increase of $5 \mathrm{~d}$; however the number of subjects studied was too small for this result to be statistically significant. Menstrual cycle length did not change on either the Arcon F diet or half-dose TVP diet.

Table 2. Mean body weights and transit times of subjects consuming a control diet or a diet containing a soyabean product over a complete menstrual cycle*

(Mean values with their standard errors)

\begin{tabular}{|c|c|c|c|c|c|c|c|c|}
\hline & \multicolumn{2}{|c|}{ Study $1(n 6)$} & \multicolumn{2}{|c|}{ Study 2 (n 3 ) } & \multicolumn{2}{|c|}{ Study $3(n 5)$} & \multicolumn{2}{|c|}{ Study 4 (n 6) } \\
\hline & Mean & $\mathbf{S E}$ & Mean & $\mathbf{S E}$ & Mean & SE & Mean & SE \\
\hline \multicolumn{9}{|l|}{ Body wt $(\mathrm{kg})$} \\
\hline Beginning of diet & $61 \cdot 6$ & $2 \cdot 4$ & $59 \cdot 0$ & 1.7 & $58 \cdot 4$ & $1 \cdot 0$ & $57 \cdot 0$ & 0.7 \\
\hline End of diet & $61 \cdot 3$ & $2 \cdot 7$ & $59 \cdot 1$ & $2 \cdot 1$ & 58.9 & $1 \cdot 2$ & 56.9 & 0.7 \\
\hline \multicolumn{9}{|l|}{ Transit time (h) } \\
\hline \multicolumn{9}{|l|}{ Follicular phase } \\
\hline Control diet & $62 \cdot 4$ & $9 \cdot 5$ & $35 \cdot 1$ & 4.7 & $43 \cdot 2$ & $10 \cdot 6$ & $47 \cdot 4$ & $9 \cdot 1$ \\
\hline Test diet $\dagger$ & $64 \cdot 3$ & 9.9 & 45.8 & $5 \cdot 3$ & 47.5 & 7.6 & $49 \cdot 6$ & $11 \cdot 3$ \\
\hline \multicolumn{9}{|l|}{ Luteal phase } \\
\hline Control diet & 55.7 & 7.9 & $46 \cdot 3$ & $7 \cdot 3$ & 58.7 & $16 \cdot 3$ & 56.8 & $14 \cdot 1$ \\
\hline Test diet $\dagger$ & $62 \cdot 2$ & $14 \cdot 0$ & $50 \cdot 5$ & $5 \cdot 3$ & 57.5 & 10.0 & $60 \cdot 1$ & $10 \cdot 3$ \\
\hline \multicolumn{9}{|l|}{ Total cycle } \\
\hline Control diet & $58 \cdot 9$ & 8.4 & $40 \cdot 7$ & 5.9 & $51 \cdot 0$ & $13 \cdot 4$ & $52 \cdot 2$ & 11.5 \\
\hline Test diet $\dagger$ & 63.8 & $12 \cdot 2$ & $48 \cdot 1$ & $5 \cdot 3$ & 52.5 & $8 \cdot 8$ & 57.3 & $10 \cdot 1$ \\
\hline
\end{tabular}

* For details of diets and procedures, see Table 1 and pp. 589-591.

$\dagger$ Study 1 , textured vegetable protein (TVP) $60 \mathrm{~g} / \mathrm{d}$; study 2 , miso $50 \mathrm{~g} / \mathrm{d}$; study 3 , Arcon F $60 \mathrm{~g} / \mathrm{d}$; study 4, TVP $28 \mathrm{~g} / \mathrm{d}$. 
HORMONAL EFFECTS OF ISOFLAVONES

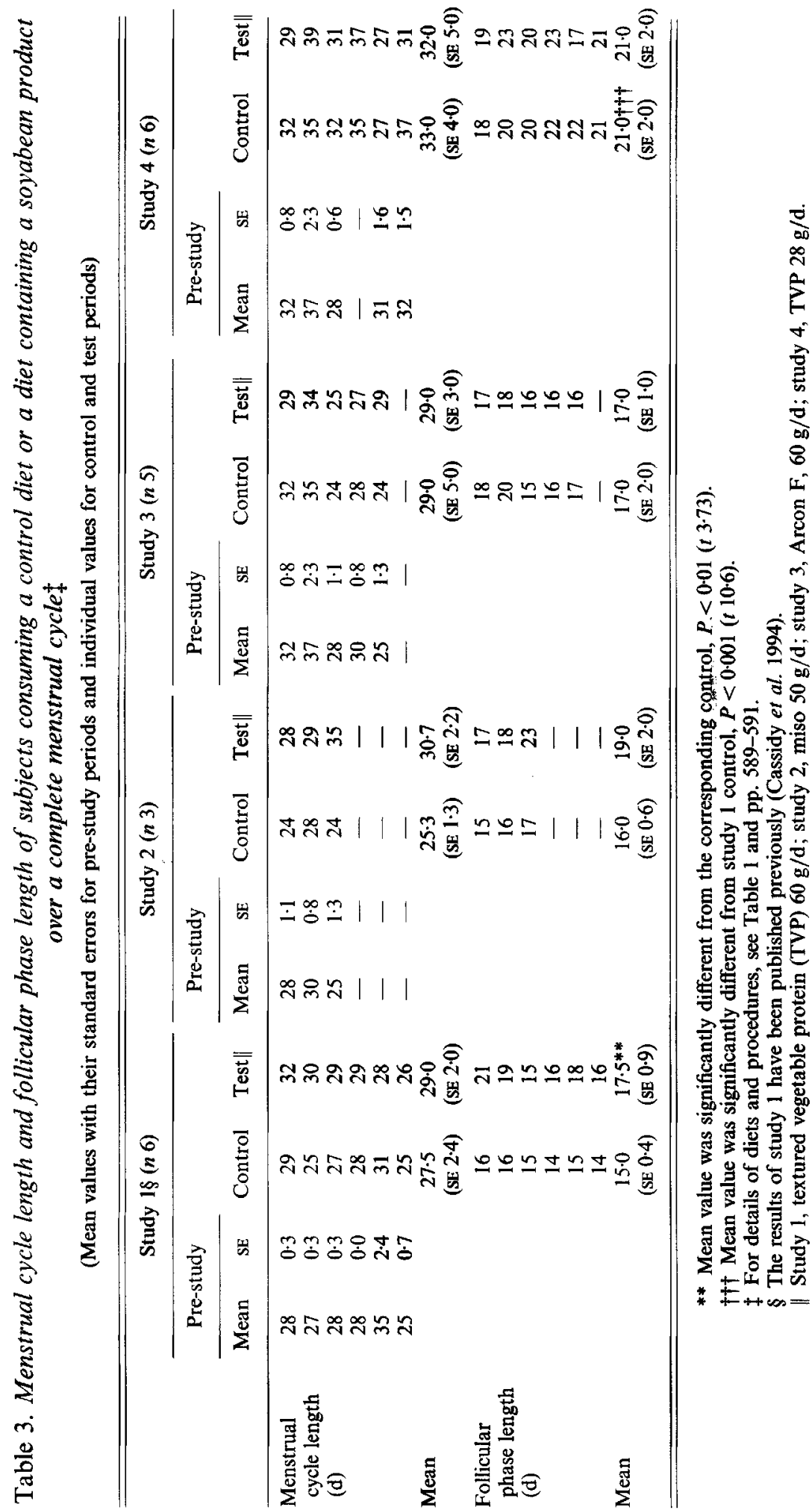




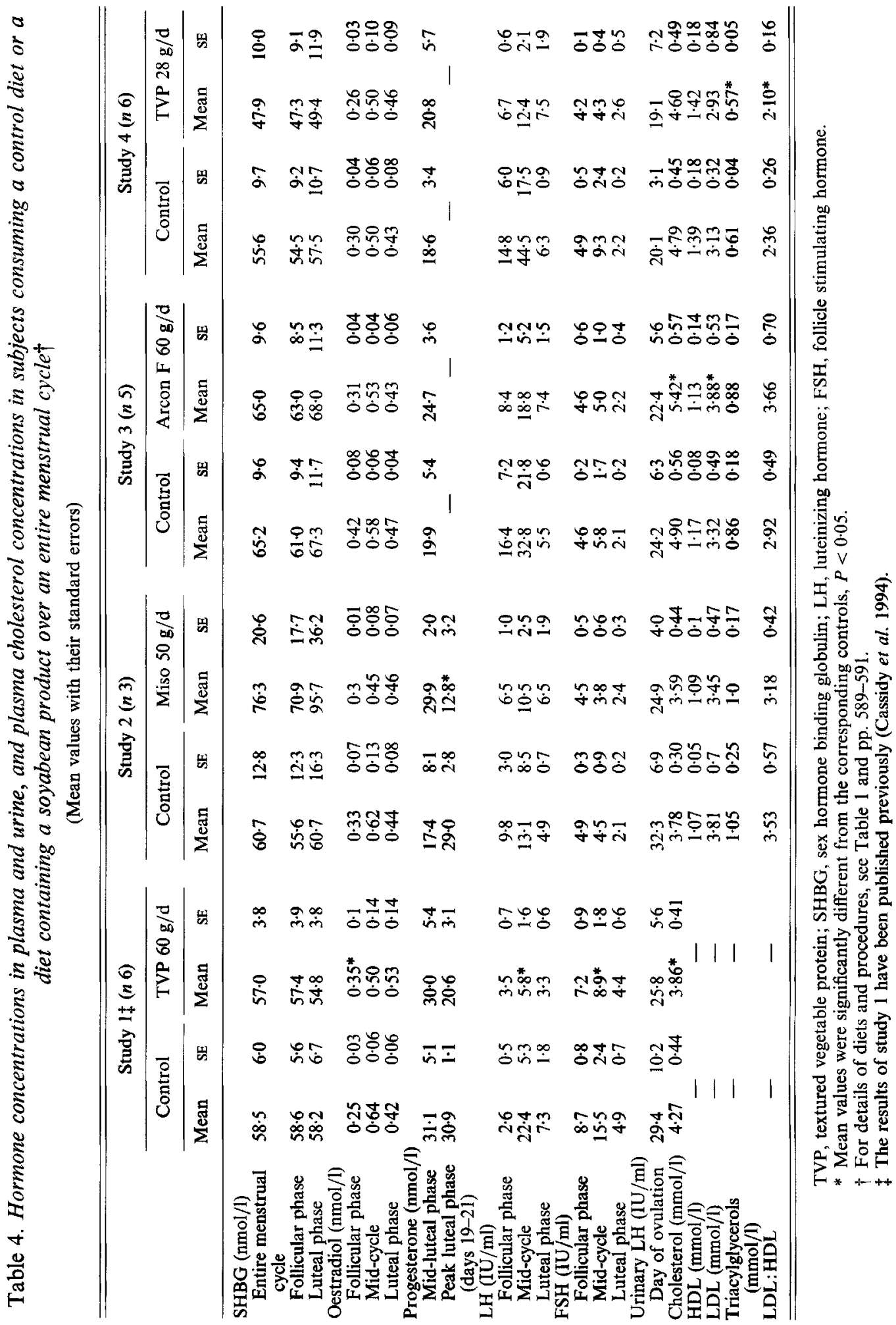



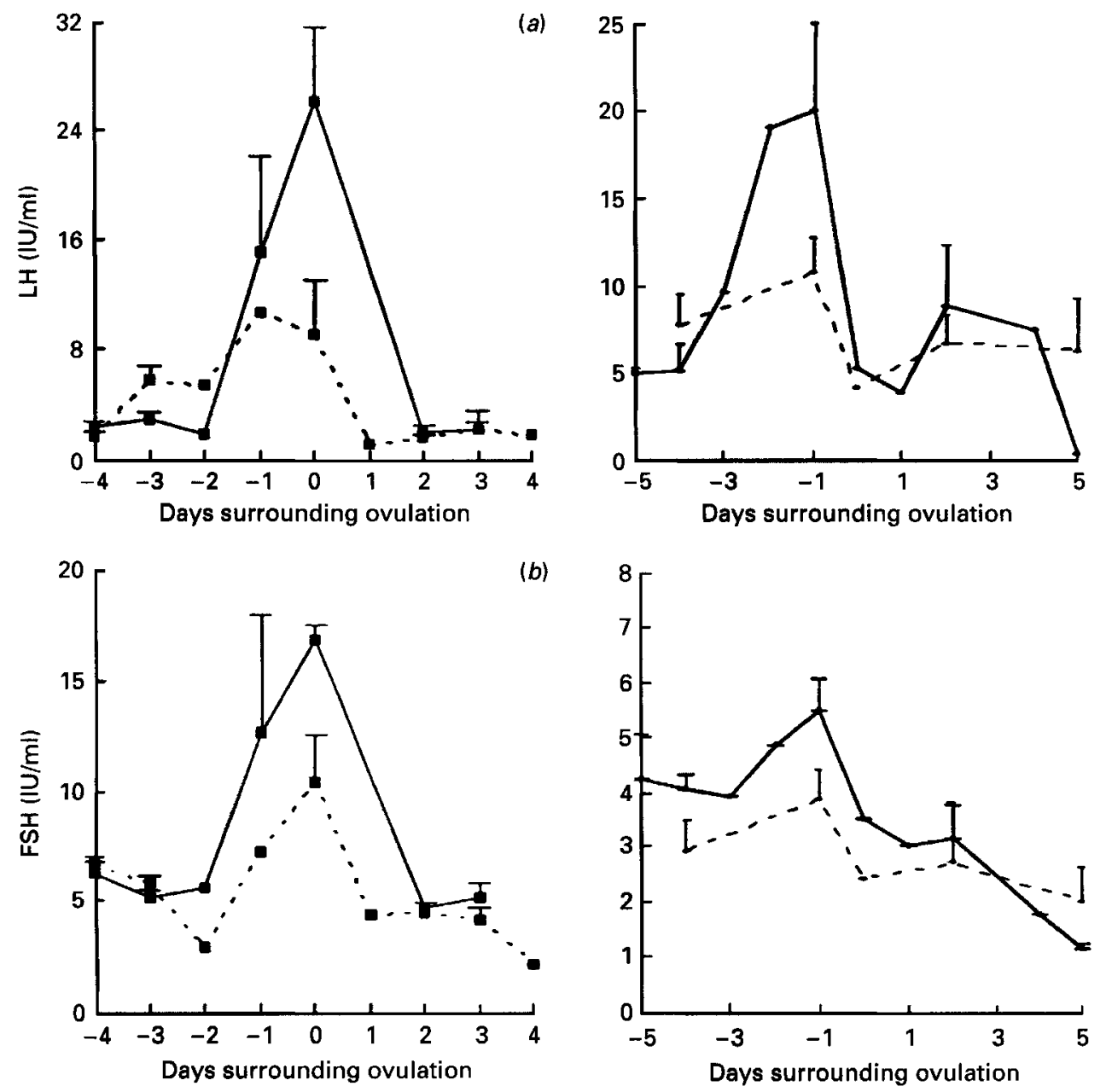

Fig. 1. (a) Luteinizing hormone (LH) and (b) follicle stimulating hormone (FSH) concentrations (IU/ml) during the 4-5 d surrounding ovulation in subjects consuming a control diet ( - or $-\square)$ or diets containing $60 \mathrm{~g}$ textured vegetable protein (TVP)/d (口--- $)$ or $50 \mathrm{~g}$ miso/d (---). Values are means for six (TVP) or three (miso) subjects, with their standard errors indicated by vertical bars. For details of diets and procedures, see Table 1 and pp. 589-591.

Follicular phase lengths during the three studies are also shown in Table 3. There was a significant difference in control follicular phase lengths between study 4 and studies 1 and 2. Mean control follicular phase length was $15 \mathrm{~d}$ in studies 1 and 2 , while mean follicular phase length was $21 \mathrm{~d}$ in study $4(P<0.001)$. Mean follicular phase length was significantly increased by $2.5 \mathrm{~d}$ by $45 \mathrm{mg}$ conjugated isoflavones used in study 1 . A trend towards an increase was observed with $25 \mathrm{mg}$ unconjugated isoflavones used in study 2 , but this did not reach statistical significance. No change in follicular phase length was observed with halfdose conjugated isoflavones, or with the isoflavone-free product.

\section{Hormone results}

Table 4 shows mean urinary LH concentrations on the day of ovulation, and mean serum/plasma LH and FSH concentrations in all four studies. The urinary results show 


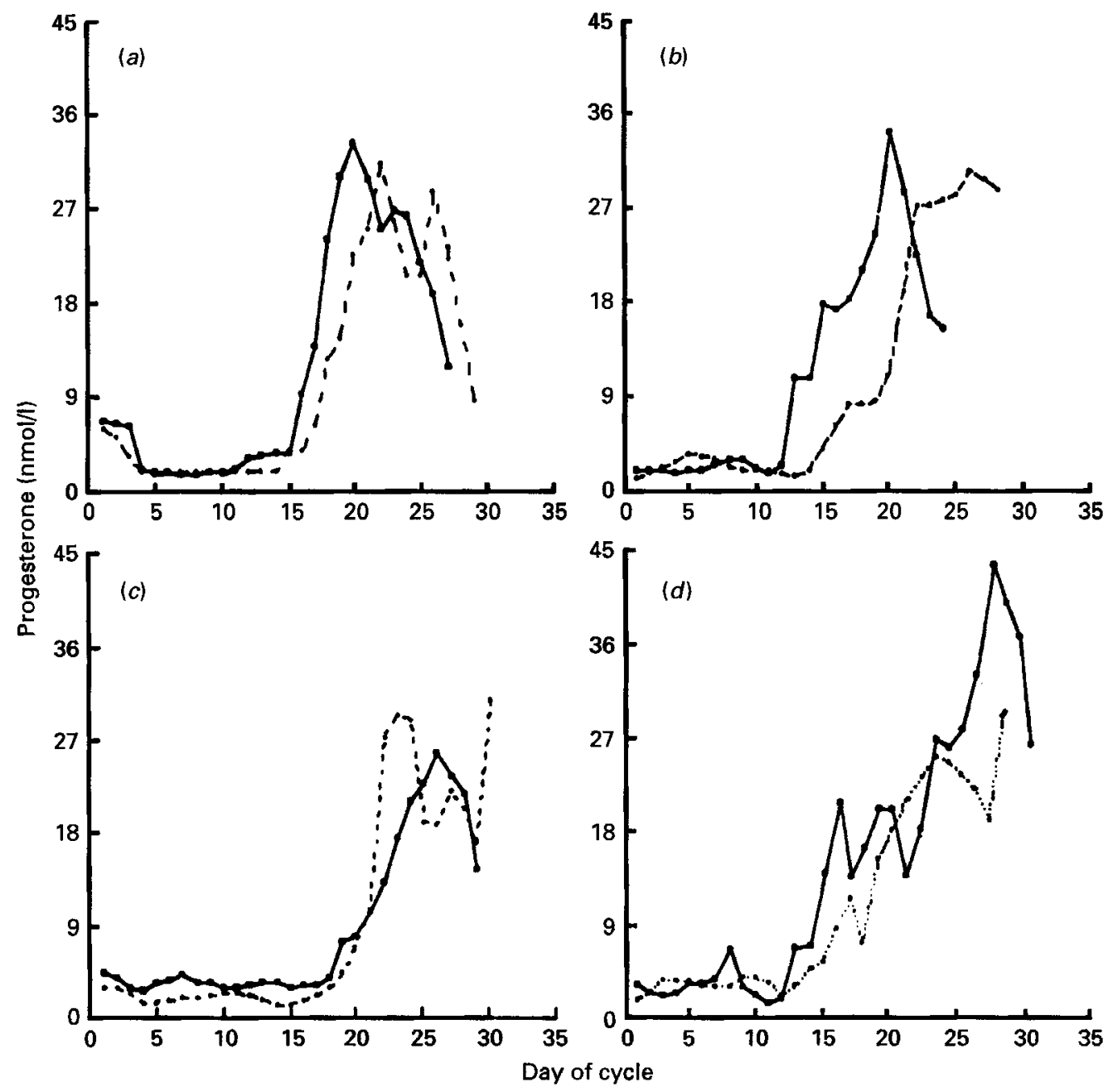

Fig. 2. Running mean ( $3 \mathrm{~d}$ average) progesterone concentrations ( $\mathrm{nmol} / 1)$ in subjects consuming a control diet ( - ) or diets containing (a) $60 \mathrm{~g}$ textured vegetable protein (TVP)/d (--); (b) $50 \mathrm{~g}$ miso/d (---); (c) $28 \mathrm{~g} \mathrm{TVP} / \mathrm{d}$ (---) and (d) $60 \mathrm{~g}$ Arcon F/d (-..-) over a complete menstrual cycle. For details of diets and procedures, see Table 1 and pp. 589-591.

that there was a trend towards a decrease in urinary LH output with $45 \mathrm{mg}$ conjugated isoflavones and $25 \mathrm{mg}$ unconjugated isoflavones; however this decrease did not reach statistical significance. Mean midcycle serum/plasma levels of LH and FSH were significantly $(P<0.05)$ suppressed by $45 \mathrm{mg}$ conjugated isoflavones in study 1 . The suppression with $25 \mathrm{mg}$ unconjugated isoflavones as miso in study 2 did not reach significance, even when the data were $\log$ transformed. There were no other significant differences in gonadotrophin levels. Fig. 1 illustrates mean group levels of LH and FSH in the 4-5 d either side of ovulation in the control diets and when $45 \mathrm{mg}$ conjugated isoflavones were consumed (study 1), and with miso in study 2, where day 0 was assigned to the day of ovulation for each subject.

Mean group mid-luteal progesterone concentrations are shown in Table 4. There were no significant differences by paired $t$ testing between control diets and those containing the 
different types of soyabean. However, the time taken to reach peak concentrations was longer with $60 \mathrm{~g}$ TVP (study 1) and this delay was significant for miso (study 2; Table 4). Fig. 2 shows $3 \mathrm{~d}$ running means for progesterone in all four studies. No significant differences in time taken to reach peak progesterone levels were observed in studies 3 or 4.

SHBG concentrations did not change significantly in any study either over the entire menstrual cycle or between the luteal phase and follicular phase of the menstrual cycle during either diet period (Table 4). Oestradiol concentrations were compared at three stages of the cycle: the follicular phase, midcycle (the three days surrounding ovulation), and the luteal phase. A significant $(P<0.05)$ increase in oestradiol level was observed during the follicular phase of the soyabean diet. No other changes in oestradiol concentrations were observed at any time in the menstrual cycle in any of the other diet periods (Table 4).

Mean total cholesterol concentrations decreased by $9 \%$ with $45 \mathrm{mg}$ conjugated isoflavones in study $1(P<0.01$; Cassidy et al. 1994), but not significantly $(P<0.05)$ with $25 \mathrm{mg}$ unconjugated isoflavones in study 2 (Table 4). LDL, total cholesterol levels and LDL:HDL ratio were significantly increased on the Arcon F diet in study 3. LDL:HDL values decreased with both $23 \mathrm{mg}$ conjugated or $25 \mathrm{mg}$ unconjugated isoflavones, but this did not reach statistical significance.

\section{DISCUSSION}

These dietary intervention studies were conducted to examine the physiological responses to different soyabean products. The effect of the chemical configuration of the isoflavones was assessed, the hormonal effects observed with a half dose of conjugated isoflavones was examined, and by showing no effects of Arcon F (isoflavone free) we could show that isoflavones are probably responsible for the observed biological effects. This confirms similar findings from animal work (Barnes et al. 1990).

Fifteen premenopausal subjects were studied over a 9-month period, 4-6 months of which were spent in a metabolic unit and 2 or 3 of these months under closely controlled conditions. In our previously published study we showed that consumption of conjugated isoflavones $(45 \mathrm{mg} / \mathrm{d})$ over a 1 -month period led to an increase in follicular phase length and menstruation was delayed in six subjects (Table 3). Midcycle surges of the gonadotrophins were significantly suppressed during dietary intervention with soyabean (Fig. 1) and the delay in menstruation was accompanied by a delay in peak luteal phase progesterone concentration (Fig. 2; Cassidy et al. 1994).

The results of these subsequent studies in protocols 2-4 also suggest that the dietary composition of isoflavones influences the observed physiological effects, unconjugated isoflavones being potentially more efficient. Unconjugated isoflavones, because of their amphiphilic properties, are probably more readily absorbed from the small intestine and are therefore more bioavailable than the highly polar conjugated species.

In study 2 we showed that half-dose unconjugated isoflavones $(25 \mathrm{mg} / \mathrm{d})$ may have exerted similar biological effects to $45 \mathrm{mg}$ conjugated isoflavones, although the small number of subjects studied reduced the power of the investigation to show significant differences in means of menstrual cycle lengths. Miso is the only rich source of unconjugated isoflavones, and its high salt content made it unpalatable to the volunteers who took part in this study. However, despite small numbers, peak progesterone concentrations were significantly delayed ( $P<0.05$; Fig. 2 ).

The levels of isoflavones given were less than the average consumption of phyto- 
oestrogens in Asian countries, which has been calculated from the daily intake of soyabean products as $50-100 \mathrm{mg} / \mathrm{d}$ (Barnes et al. 1990; Coward et al. 1993). The doses used in these intervention studies were therefore physiological. The $60 \mathrm{~g}$ TVP necessary to induce effects can be easily consumed in a single meal, but study 4 provided little evidence to suggest that smaller amounts of conjugated isoflavones $(23 \mathrm{mg} / \mathrm{d})$ as $28 \mathrm{~g}$ TVP had an effect on the physiological regulation of the menstrual cycle or on midcycle surges of the gonadotrophins, in contrast to those found with the unconjugated form, in miso, at the same dose. However, control follicular phase length was significantly longer in the subjects studied in study 4 than in studies 1 and 2.

There was no significant difference in cycle length between control and pre-study periods (Table 3), which suggests that living in the metabolic suite and eating the control diet had no effect on cycle length. Menstrual cycle lengths were within the expected range for this age group, because previous studies have shown the 5 th-95th percentile range of usual cycle length to vary from 24-33 d (Munster et al. 1992), 24-36 d (Treolar et al. 1967) and 23-39 d (Vollman, 1977) for women aged between 25 and 34 years. Interassay coefficients of variation were not substantially different for the hormone assays by either TRF or RIA, thus a direct comparison of the hormone data from the four studies was valid. In addition, because each subject acted as her own control, and each hormone was analysed by the same method for both test and control periods, a direct comparison of the methods is valid.

Soyabean protein has been shown to lower total cholesterol levels of both hypercholesterolaemic and normocholesterolaemic subjects (Carroll, 1991). However, the mechanism and component of soyabean responsible for this hypocholesterolaemic effect have not been elucidated. Suggested mechanisms include upregulation of the LDL receptor, or an increase in bile acid synthesis (Carroll, 1991). The results from the studies reported here suggest that isoflavones present in soyabean may be responsible for the hypocholesterolaemic effects. Reductions in total cholesterol levels of $9 \%$ and $5 \%$ were observed during diets with both conjugated and unconjugated isoflavone products respectively and a trend towards a decrease in LDL: HDL value was observed with $23 \mathrm{mg}$ conjugated or $25 \mathrm{mg}$ unconjugated isoflavones.

There were unexpected significant increases in total and LDL-cholesterol concentrations and LDL:HDL value on the Arcon F diet. Although calculated total fat intake was similar in all the dietary studies, a hardened margarine was used to make the biscuits. Levels of trans, polyunsaturated and saturated fatty acids may have been different in study 3 although the computerized database (Paul \& Southgate, 1978) used to calculate intake did not contain values for constituent fatty acids. Both trans and saturated fatty acids are known to increase blood cholesterol levels (Oliver, 1982; Willett et al. 1993).

The physiological effects of plant oestrogens are likely to have implications for sexhormone related conditions, in addition to ischaemic heart disease, for which total cholesterol, LDL-cholesterol, and the LDL:HDL value are known to be important risk factors (Oliver, 1982). Vegetarian women who excrete high concentrations of plant oestrogens (Adlercreutz et al. 1982, 1986) are reported to have irregular menstrual cycles (Pedersen et al. 1991), although the possibility that this is related to higher consumption of isoflavones or other plant oestrogens has not been investigated.

The hormonal changes observed in the current study, decreases in circulating levels of LH and FSH, are similar to those observed with the synthetic antioestrogen, Tamoxifen, which is successfully used in breast cancer therapy (Golder et al. 1976; Willis et al. 1977; Jordan et al. 1987). The hormonal and menstrual cycle modifications induced by soyabean protein are also related to risk factors for breast cancer. Risk is thought to be related both to oestrogen exposure and to the cumulative number of menstrual cycles a women experiences over her premenopausal years (Henderson et al. 1995). Japanese women have a fourfold 
lower risk for breast cancer than Western women (Muir et al. 1987) and a longer menstrual cycle length. Mean cycle length in developed countries, where breast cancer risk is high, is 28-29 d (World Health Organization, 1983; Henderson et al. 1985; Munster et al. 1992), while an average recall cycle length of $32 \mathrm{~d}$ was reported in low-risk Japanese women at age 25 years (Treolar et al. 1967). Epithelial cells of the terminal duct lobular unit, from which the majority of breast cancers arise, undergo significant changes during the menstrual cycle. In the terminal duct lobular unit, cell proliferation rate is relatively low during the follicular phase and then increases by a factor of two in the mid-to late lutual phase (Ferguson \& Anderson, 1981). The major part of variation in cycle length is in the length of the follicular phase (Arksol, 1981; Lenton et al. 1983). Women with longer cycles will therefore have longer follicular phases, resulting in reduced breast-cell division over their premenopausal years.

In conclusion, these dietary intervention studies show that diet can modify hormonal status in normal ovulating women and that different types of plant oestrogens are probably responsible for the observed biological effects. These findings suggest that the plant oestrogens present in soyabean were exerting an oestrogenic or inhibitory effect on the hypothalamic-pituitary-gonadal axis.

The volunteers who took part in this study are thanked for their invaluable help. Janet Beck, Judith Wills and Elaine Collard are thanked for technical assistance. The study was supported in part by the National Institute for Health, USA and The Ministry of Agricultural Fisheries and Foods, UK.

\section{REFERENCES}

Adlercreutz, H., Fotsis, T., Heikkinen, R., Dwyer, J. T., Woods, M., Goldin, B. R. \& Gorbach, S. L. (1982). Excretion of the lignans enterolactone and enterodiol and of equol in omnivorous and vegetarian postmenopausal women and in women with breast cancer. Lancet 2, 1295-1299.

Adlercreutz, H., Fotsis, T., Bannwart, C., Wahala, K., Makela, T., Brunow, G. \& Hase, T. (1986). Determination of urinary lignans and phytoestrogen metabolites, potential antiestrogens and anticarcinogens, in the urine of women on various habitual diets. Journal of Steroid Biochemistry 25, 791-797.

Arksol, S. (1981). Hormonal characteristics of long cycles in fertile women. Fertility Sterility 36, 521-523.

Barnes, S., Grubbs, C., Setchell, K. D. R. \& Carlson, J. (1990). Soyabeans inhibit mammary tumor growth in models of breast cancer. In Mutagens and Carcinogens in the Diet, pp. 239-253 [M. W. Pariza, editor]. New York: Wiley-Liss.

Bingham, S. \& Cummings, J. H. (1983). The use of 4-amino benzoic acid as a marker to validate the completeness of 24 hour urine collections in man. Clinical Science 64, 629-635.

Carroll, K. K. (1991). Review of clinical studies on cholesterol lowering response to soy protein. Journal of the American Dietetic Association 91, 820-827.

Cassidy, A., Bingham, S. \& Setchell, K. (1994). Biological effects of isoflavones present in soy in premenopausal women: implications for the prevention of breast cancer. American Journal of Clinical Nutrition 60, 333-340.

Clark, J. H., Paszka, A. \& Peck, E. J. (1977). Nuclear binding and retention of the receptor oestrogen complex. Relation to the agonistic and antagonistic properties of oestradiol. Endocrinology 100, 91-96.

Coward, L., Barnes, N. C., Setchell, K. D. R. \& Barnes, S. (1993). The isoflavones genistein and daidzein in soy based foods from American and Asian diets. Journal of Agriculture and Food Science 41, 1961-1967.

Cummings, J. H., Jenkins, D. J. A. \& Wiggins, H. S. (1976). Measurement of the mean transit time of dietary residue through the human gut. Gut 17, 210-218.

Evans, J. A., Varney, R. F. \& Koch, F. C. (1941). The mouse uterine weight method for the assay of estrogens. Endocrinology 28, 747-749.

Ferguson, D.J.P. \& Anderson, T. J. (1981). Morphological evaluation of cell turnover in relation to the menstrual cycle in the 'resting' human breast. British Journal of Cancer 44, 177-181.

Folman, Y. \& Pope, G. S. (1966). The interaction in the immature mouse of potent oestrogens with coumestrol, genistein and other utero-vaginotrophic compounds of low potency. Journal of Endocrinology 34, 215-225.

Golder, M. P., Phillips, E. A., Fahmy, D. R., Preece, P. E., Jones, V., Henk, J. M. \& Griffiths, K. (1976). Plasma hormones in patients with advanced breast cancer treated with Tamoxifen. European Journal of Cancer 12, 719-723. 
Hawrylewicz, E. J., Huang, H. H. \& Blair, W. H. (1991). Dietary soya bean isolate and methionine supplementation affect mammary tumour progression in rats. Journal of Nutrition 121, 1693-1698.

Henderson, B. E., Ross, R. K., Judd, H. L., Krailo, M. D. \& Pike, M. C. (1985). Do regulatory ovulatory cycles increase breast cancer risk? Cancer 56, 1206-1208.

Hirayama, T. (1986). A large scale cohort study on cancer risks by diet - with special reference to the risk reducing effects of green-yellow vegetable consumption. In Diet, Nutrition and Cancer, pp. 41-53 [Y. Hayashi, M. Nagao, T. Sugimura, S. Takayama, L. Tomatis, L. W. Wattenburg and G. N. Wogan, editors]. Utrecht, The Netherlands: Tokyo/VNU Sci Press.

Jordan, V. C. (1990). The only true antiestrogen is a no estrogen. Molecular and Cellular Endocrinology 74, C91.

Jordan, V. C., Fritz, N. F. \& Tormey, D. C. (1987). Endocrine effects of adjuvant chemotherapy and long-term Tamoxifen administration on node-positive patients with breast cancer. Cancer Research 47, 624-630.

Juniewicz, P. E., Pallante Morell, S., Moser, A. \& Ewing, L. L. (1988). Identification of phytoestrogens in the urine of male dogs. Journal of Steroid Biochemistry 31, 987-994.

Katzenellenbogen, J. A., Ferguson, E. R. \& Lan, N. C. (1977). Fundamental differences in the action of oestrogens and antioestrogens on the uterus. Comparison between compounds with similar duration of action. Endocrinology 100, 1252-1259.

Lee, H. P., Gourley, L., Duffy, S. W., Esteve, J., Lee J. \& Day, N. E. (1991). Dietary effects on breast cancer risk in Singapore. Lancet 337, 1197-1200.

Lenton, E. A., Lawrence, G. F., Coleman, R. A. \& Cooke, I. D. (1983). Individual variation in gonadotrophin and steroids and in the lengths of the follicular and luteal phases in women with regular menstrual cycles. Clinical Reproduction and Fertility 2, 143-150.

Martin, P. M., Horwitz, K. B., Ryan, D. S. \& McGuire, W. L. (1978). Phytoestrogens interaction with estrogen receptors in human breast cancer cells. Endocrinology 103, 1860-1867.

Muir, C., Waterhouse, J., Mack, T., Powell, J. \& Whelan, S. (1987). Cancer Incidence in Five Continents, vol. 5. International Agency for Research on Cancer Scientific Publication no. 88. Lyon, France: IARC.

Munster, K., Schmidt, L. \& Helm, P. (1992). Length and variation in the menstrual cycle. A cross sectional study from a Danish county. British Journal of Obstetrics and Gynaecology 99, 422-429.

Nomura, A., Henderson, B. E. \& Lee, J. (1978). Breast cancer and diet among the Japanese in Hawaii. American Journal of Clinical Nutrition 31, 2020-2025.

Oliver, M. F. (1982). Diet and coronary heart disease. Human Nutrition: Clinical Nutrition 36C, 413-427.

Paul, A. A. \& Southgate, D. A. T. (1978). McCance and Widdowson's The Composition of Foods, 4th ed. London: H.M. Stationery Office.

Pedersen, A. B., Bartholomew, M. J., Dolence, L. A., Aljadir, L. P., Netteburg, K. L. \& Lloyd, T. (1991). Menstrual differences due to vegetarian and nonvegetarian diets. American Journal of Clinical Nutrition 53, 879-884.

Schofield, N. W., Schofield, C. \& James, W. P. T. (1985). Basal metabolic rate. Human Nutrition: Clinical Nutrition 39C, Suppl. 1, 1-96.

Setchell, K. D. R., Borriello, S. P., Hulme, P. \& Axelson, M. (1984). Nonsteroidal estrogens of dietary origin: possible roles in hormone-dependent disease. American Journal of Clinical Nutrition 40, 569-578.

Setchell, K. D. R., Welsh, M. \& Lim, C. K. (1987). High-performance liquid chromatographic analysis of phytoestrogens in soy protein preparations with ultraviolet, electrochemical and thermospray mass spectrometric detection. Journal of Chromatography 386, 315-323.

Shemesh, M., Lindner, H. R. \& Ayalon, N. (1972). Affinity of rabbit uterine oestradiol receptor for phytoestrogens and its use in a competitive protein-binding radioassay for plasma coumestrol. Journal of Reproduction and Fertility 29, 1-6.

Shutt, D. A. (1967). Interaction of genistein with oestradiol in the reproductive tract of the ovariectomised mouse. Journal of Endocrinology 37, 231-232.

Shutt, D. A. \& Cox, R. I. (1972). Steroid and phytoestrogen binding to sheep uterine receptors in vitro. Journal of Endocrinology 52, 299-310.

Treolar, A. E., Boynton, R. E., Behn, B. G. \& Brown, B. W. (1967). Variation of the human menstrual cycle through reproductive life. International Journal of Fertility 12, 77-126.

Troll, W., Wiesner, R., Shellabarger, C. J., Holtzman, S. \& Stone, J. P. (1980). Soybean diet lowers breast tumour incidence in irradiated rats. Carcinogenesis 1, 469-472.

Verdeal, K., Brown, R. R., Richardson, T. \& Ryan, D. S. (1980). Affinity of phytoestrogens for estradiol-binding proteins and effect of coumestrol on growth of 7,12-dimethylbenz $(\alpha)$ anthracene-induced rat mammary tumors. Journal of the National Cancer Institute 64, 285-290.

Vollman, R. F. (1977). The menstrual cycle. Major Problems in Obstetrics and Gynaecology, vol 7, pp. 56-101. Philadelphia: W. B. Saunders Co.

Willett, W. C., Stampfer, M. J., Manson, J. E., Colditz, G. A., Speizer, F. E., Rosner, B. A., Sampson, L. A. \& Hennekens, C. H. (1993). Intake of trans fatty acids and risk of coronary heart disease among women. Lancet 341, 581-585. 
Willis, K. J., London, D. R., Ward, H. W. C., Butt, W. R., Lynch, S. S. \& Rudd, B. T. (1977). Recurrent breast cancer treated with the antiestrogen tamoxifen: correlation between hormonal changes and clinical course. British Medical Journal i, 425-428.

World Health Organization (1983). A prospective multicenter trial of the ovulation method of natural family planning. III. Characteristics of the menstrual cycle and of the fertile phase. Fertility Sterility 40, 773-778. 